\title{
Research on the Technology of Urban Road Traffic System
}

\author{
Weiling Teng ${ }^{1}$ \\ Xijing University, 710123, Xi'an, China \\ e-mail: 370374964@qq.com \\ Shidan $\mathrm{He}^{3}$ \\ Xijing University, 710123, Xi'an, China \\ e-mail: 315705804@qq.com
}

\author{
Xiaofang $\mathrm{Li}^{2}$ \\ Xijing University, 710123, Xi'an, China \\ e-mail: lixiaofangxijing@126.com
}

\begin{abstract}
Urban road traffic system is a system which is a collection of its internal factors, complex open, large randomized controlled. It has the basic characteristics of relevance, dynamic balance and structural. The characteristics of urban road traffic system determine the complexity that problems. Despite the rapid increase about the supply ability of urban road traffic system, the urban road traffic problems did not get substantial solution. Urban road traffic system and city scale "interaction expansion", the vicious inflation does not only increase the residents' travel cost, but also makes the whole society pay a high price.
\end{abstract}

Keywords-Urban road; The traffic system; economic evaluation

\section{INTRODUCTION}

In recent years, China's sustained economic growth, urbanization and industrialization process are significantly speeding up; on the other hand, the urban traffic demand is also rising sharply. Most cities have set up the corresponding traffic line network and traffic facilities, Jackson and Kernel[1]which is in order to meet the needs of urban rapid development that economy and society,during urban traffic, has entered a rapid development period. However, the present situation of the urban traffic system current in China is as follows (Omcason[2]): on one hand, the government raised for urban transportation infrastructure investment year by year; on the other hand, urban traffic problems are highlighted (Hlifton [3]), road traffic is crowded, people have difficulties and have to cost a long time to travel. There are also many problems in the development of the traffic of the city. The characteristics of urban road traffic system determine the complexity of those problems. Despite the rapid increase about the supply ability of urban road traffic system, the urban road traffic problems do not get substantial solutions. Urban road traffic system and city scale "interaction expansion", and the vicious inflation does not only increase the residents' travel costs, but also makes the whole society pay a high price. Based on the basic characteristics of urban road traffic system, from the perspective of economics, combining with the technical characteristics of urban road traffic system, on the basis of qualitative analysis of the mechanism, by means of quantitative economic evaluation, this paper constructs the theory model of technical and economic evaluation of urban road traffic system, and puts forward the urban road traffic system "unit capacity cost" the core evaluation index.

\section{THE DISJOINT OF URBAN TRAFFIC PLANNING AND LAND PLANNING}

At the beginning of the rapid development of urbanization of China, such as management system, planning and policy issues of urban traffic planning and urban land planning in the disconnected state[4]. As urban traffic planning increasingly prominent, people keep trying synchronous coordinate the relationship between the transportation planning and land planning, which attend the phenomenon to appear frequently. The solve traffic problem has worsened in many cities instead. The phenomenon of excessive concentration is not only failed to ease ,but also be rather worse. "Booth pie", "lies the city" have become the associated words with almost the traffic problems of cities today.

Firstly, transport supply and demand contradiction. With the constant economic development in China, many cities have attached great importance to traffic infrastructure construction. Traffic congestion problems, however, did not ease, what's more, the traffic demand cannot be satisfied.

Secondly, the rapid growth of motor vehicle. The average annual China's vehicle increases more than $15 \%$ and the existing urban road network in China is widespreading the shortage of low density. Road spacing is too large, branch, and the function structure has chaotic problems.

Finally, the public transportation development faces difficulties.many cities made the grand plans for the development of public transportation, and put forward the "bus priority development". A comprehensive passenger bus is established as the main body in a variety of ways, that to coordinate operation system of the strategic objectives. The large increase in public transportation capacity do not bring the public transportation proportion corresponding growth, and some cities even have declined. our city's public transportation is still on the bus all the way, such as Beijing, Shanghai, Tianjin, Shenzhen, 
Guangzhou, Nanjing and other large cities, where have the subway, light rail and other rail public transportation lines. Therefore, once a single bus transferred out of traffic demand to find a way out, the most attractive is the private cars.

\section{THE TECHNICAL AND ECONOMIC EVALUATION IN URBAN ROAD TRAFFIC SYSTEM}

Urban road traffic system is controlled system which a collection of its internal factors[5]. It has the basic characteristics of relevance, dynamic balance and structural. This article attempts from the perspective of economics and combines with related technical indicators selection[6]. How much for the road traffic system in city elements, and how much utility is the investment for the urban road traffic system output.

\section{SELECTION OF URBAN ROAD TRAFFIC SYSTEM INPUTS}

Land occupied for construction fund input and pollution control investment and system are derived[7]. Among them, the construction funds are the basic urban road traffic system, the construction of urban road traffic system operation and management, which have a fundamental role; land is the material basis for the existence, that is the important material carrier of the urban road traffic system; city scale caused the rapid enlargement rapid expansion of urban road traffic system and the expansion of the urban road traffic system will bring a series of derivatives in city. Thus, the selection of urban road traffic system inputs give full consideration to the basic attributes, material is can satisfy the essential demand of technical and economic evaluation. Computation formula is as follows[8]:

$$
C_{\mathrm{fb}}=\sum \mathrm{a}_{1 \mathrm{j}} \times I_{i}
$$

$C_{f b}$ is Urban traffic basic fee; $a_{1 j}$ is unit cost of

Urban main road, main road, time, number of branch

TABLE I THE COST OF DIFFERENT TYPES OF ROAD UNIT MILEAGE IS TEN THOUS AND /KM

\begin{tabular}{|c|c|}
\hline The way & Cost \\
\hline Fast trunk & $2000-4000$ \\
\hline road & $1500-2000$ \\
\hline The main road & $950-1200$ \\
\hline Trunk road & $500-750$ \\
\hline City bridge & $12000-21000$ \\
\hline
\end{tabular}

\section{THE SELECTION OF URBAN ROAD TRAFFIC SYSTEM OUTPUT ELEMENTS}

In this paper, the urban road traffic system technical economic evaluation methods are studied. Based on the basic characteristics of urban road traffic system, from the perspective of economics, combining with the technical characteristics of urban road traffic system, on the basis of qualitative analysis of the mechanism, by means of quantitative economic evaluation, this paper constructs the theory model of technical and economic evaluation of urban road traffic system, and puts forward the urban road traffic system "unit capacity cost" the core evaluation index. The main consideration capacity output, which saves time output and output of land value increment. the capacity of output is based on the main technical indicators of urban road traffic system capacity, the urban road traffic system is the main function thus, saving production time is on urban road traffic system can bring much convenience for city residents travel objective evaluation index. Selection of urban road traffic system output elements is the technical level of the urban road traffic system, and service the direct object of three levels.

TABLE II CITY FORK CORRECTION COEFFICIENT

\begin{tabular}{|c|c|}
\hline The way & Coefficient \\
\hline Fast trunk & 0.9 \\
\hline road & 0.7 \\
\hline The main road & 0.5 \\
\hline Trunk road & 0.4 \\
\hline City bridge & 0.3 \\
\hline
\end{tabular}

\section{THE ESTABLISHMENT OF THE TECHNICAL AND ECONOMIC EVALUATION SYSTEM OF URBAN ROAD TRAFFIC SYSTEM}

The technical and economic evaluation for urban road traffic system is based on the basic principle of economics, and combining with related technical indicators, adopting the method of "input output". The evaluation system as shown in figure1.

Qualitative description and quantitative model,the structure of technical and economic evaluation model of urban road traffic system, as follows[9]: 


$$
\mathrm{PCC}=\frac{\left(\mathrm{C}_{\mathrm{F}}+\mathrm{C}_{\mathrm{L}}+\mathrm{C}_{\mathrm{P}}+\mathrm{C}_{\mathrm{D}}\right)-\left(E_{\mathrm{TS}}+\mathrm{E}_{\mathrm{LA}}\right)}{C_{N}}
$$

PCC is The urban traffic system of the unit cost

$$
\mathrm{C}_{\mathrm{F}}=\mathrm{C}_{\mathrm{FB}}+\mathrm{C}_{\mathrm{FK}}+\mathrm{C}_{\mathrm{FR}}+\mathrm{C}_{\mathrm{FM}}
$$

$\mathrm{C}_{\mathrm{L}}$ is the Land use is put in

$\mathrm{C}_{\mathrm{p}}$ is the Pollution in

$\mathrm{C}_{\mathrm{D}}$ is the Derivatives in

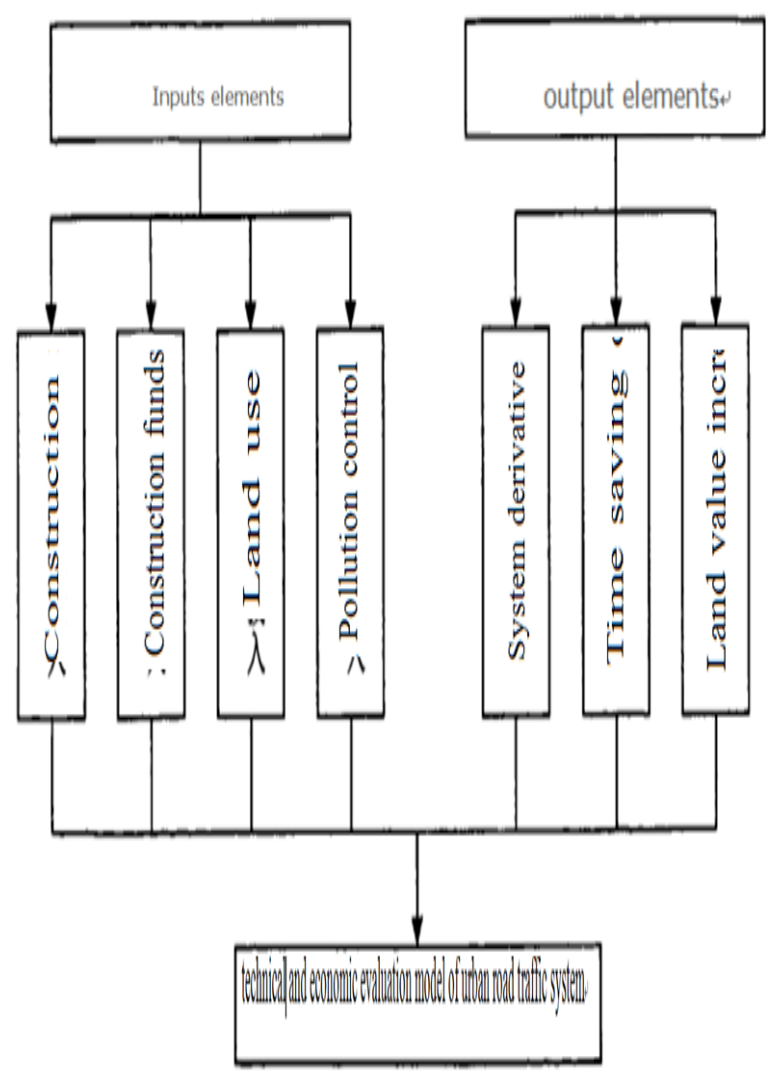

Figure 1. technical and economic evaluation model of urban road traffic system

\section{TECHNICAL AND ECONOMIC EVALUATION MODEL OF URBAN ROAD TRAFFIC SYSTEM APPLICATIONS}

The technical and economic evaluation model of urban road traffic system and the evaluation results by "unit capacity cost" to represent the core indicators. "Unit capacity cost " is under the given condition, which provides a unit of capacity to pay the cost. The core indicators do not only simply and clearly show the technical and economic evaluation of urban road traffic system eventually quantitative results, but also measure the important parameters of an urban road traffic policy implementation effect.

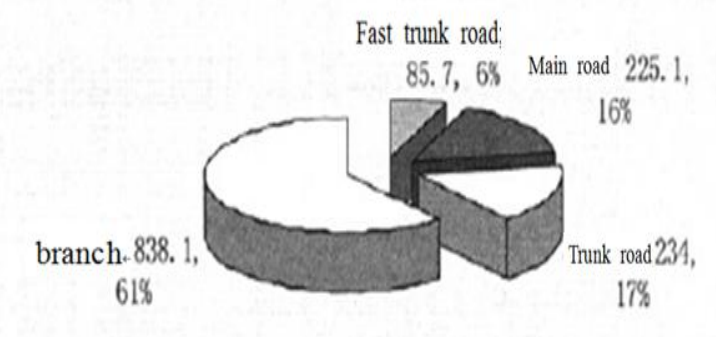

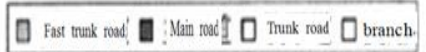

Figure 2. network structure of road

\section{THE APPLICATION OF ESTABLISHED UNDER ABOUT "UNIT CAPACITY COST"}

From technical and economic evaluation of urban road traffic system, the paper analyses the mechanism of urban road traffic system can be drawn from the index of "unit capacity cost", which is the indicator of urban road traffic system of "one state" of the technical and economic evaluation; both qualitative analysis of the research and quantitative research of data acquisition are carried out under a given condition[10]. Therefore, the significance of the index "unit capacity cost" itself is to "quantitative" that under the condition of a certain technology, a given state of "the economic costs of urban road traffic system; it is also based on the" economic equilibrium "moderate scale of urban development research one of the important theoretical basis.

"unit capacity cost than under different state" of the application

"Unit capacity cost than" is put forward. "Unit capacity cost" is an important indicator, since to the established state technical and economic evaluation of urban road traffic system; so under different condition, the corresponding comparative evaluation of urban road traffic system is feasible in theory. As a result, can lead to different stages of the concept of "unit capacity cost than"

\section{IX. "UNIT CAPACITY COST THAN" EXAMPLE UNDER DIFFERENT STATUS OF THE APPLICATION}

"Unit capacity cost" proposes that it is related to urban road traffic system to evaluate the implementation effect of public policy. A certain city in the year, for example, the urban road traffic system is put forward for the development of a plan, and if you want to know how effective the implementation of this plan, you can for the first year of policy implementation status, and the evaluation of years after the policy implementation would be a state. Through the different stages of "the calculation of unit capacity cost", "unit capacity cost ratio are obtained.

\section{CONCLUSIONS}

In view of the current main problems of urban road traffic system in China, in this paper, the urban road traffic system technical economic evaluation methods are studied. 
Based on the basic characteristics of urban road traffic system, from the perspective of economics, combining with the technical characteristics of urban road traffic system, on the basis of qualitative analysis of the mechanism, by means of quantitative economic evaluation, this paper constructs the theory model of technical and economic evaluation of urban road traffic system and puts forward the urban road traffic system "unit capacity cost" core evaluation index. The index has both technical and economical efficiency of the urban road traffic system state evaluation and the field layout parameters selection, policy implementation effect evaluation has important theoretical and practical value. Urban road traffic system is a system which is a collection of its internal factors, complex open, large randomized controlled. It has the basic characteristics of relevance, dynamic balance and structural. The characteristics of urban road traffic system determine the complexity that problems. Despite the rapid increase about the supply ability of urban road traffic system, the urban road traffic problems do not get substantial solution. Urban road traffic system and city scale "interaction expansion ", the vicious inflation does not only increase the residents' travel cost, but also makes the whole society pay a high price.

\section{REFERENCES}

[1] Chen Jinchuan. China's urban transportation problem analysis and improvement countermeasures [J]. Journal of urban traffic, 2007, 5 (4) : 5-9
[2] Zhao-sheng Yang, wang miao. Grey statistics of urban traffic system [J]. Highway traffic science and technology, 1999 (2) : 49.52

[3] Wang Yuanyuan hua-pu lu, Qin Xuyan. Based on the grey clustering analysis of urban traffic road network comprehensive evaluation method research $[\mathrm{J}]$. Highway traffic science and technology, 2005, (8) : 118.121

[4] Xi-bang fang, Yu Jingfei Xia Bangjin. Urban traffic system development level evaluation system and method research [J]. Journal of hefei university of technology (natural science edition), 2005, (3) : 239.241

[5] Yang-sheng jiang, Chen Yanru. Coordination of the development of the analysis of urban traffic system [J]. Journal of transportation engineering and information technology, 2006, (3) : 53-56

[6] Xiu-zhi guo, hua-pu lu. The urban traffic system as a whole development level of comprehensive evaluation index system and method [J]. Transportation standardization, 2003, 8:53-54

[7] Yu-mei jiang, huai-cheng guo kai huang, YuYaJuan, lehmann m. sustainability. Urban ecological transport system comprehensive evaluation method and its application $[\mathrm{J}]$. Journal of environmental science research, 2007, 20 (6) : 158.163

[8] Jameslu glowei. Facing the sustainable development of urban traffic system comprehensive evaluation method research $[\mathrm{J}]$ Journal of civil engineering, 2004, 5 (3) : 99-104

[9] Zhu Dayou, li xue. Comprehensive evaluation for the sustainable development of urban traffic system [J]. Transportation standardization, 2005, 11:76-79

[10] Zhang jun, toleman, zhao month, also provided. The coordinated development of urban traffic system based on DEA evaluation study $[\mathrm{J}]$. Computer engineering and application, 2007 lancet (32) : 245-255. 